\title{
Reklamlarda Üçüncü Kişi Algısının Yanlı İyimserlik Bağlamında Değerlendirilmesi: Türkiye ve Kanada Karşılaştırması*
}

\author{
Nezahat Ekici1 이, Bayram Zafer Erdoğan² (]
}

Öz

Bu çalışmanın amacı üçüncü kişi algısı ve yanlı iyimserlik gibi psikolojik temelli iki kavram arasındaki etkileşimin cinsel içerikli reklamlar ve satın alma niyeti özelinde irdelenmesidir. Bu amaçla, kolayda örnekleme yöntemiyle Kanada ve Türkiye'deki üniversite öğrencilerinden anket yardımıyla elde edilen veriler analiz edilmiştir. Verilerin analizinde 2X4 MANOVA kullanılmıştır. Araştrma sonuçlarına göre ürün hedonik olduğunda bireylerin kültürel geçmişi ve yanlı iyimserlik düzeyleri algısal ve davranışsal boşluk üzerinde birlikte bir etkiye sahip değilken, ürün faydacı olduğunda bu iki faktör algısal boşluk üzerinde marjinal düzeyde anlamlı, davranısssal boşluk üzerinde ise anlamlı düzeyde birlikte bir etkiye sahiptir. Elde edilen sonuçların kültür bağlamında medya etkileri, reklamcılık ve tüketici davranışı üzerine çalışan araştırmacı ve uygulamacılara katkı sağlaması beklenmektedir.

\section{Anahtar Kelimeler \\ Üçüncü kişi algısı, Yanlı iyimserlik, Satın alma niyeti, Cinsel içerikli reklamlar \\ Examining Third-Person Perception in Advertisements within the Context of Optimistic Bias: A Comparison of Turkey and Canada}

\begin{abstract}
The aim of this study is to examine the interaction between the concepts of third-person perception and optimistic bias - which are highly based on psychology - in the context of suggestive advertisements and purchase intention. For that purpose, data was used drawn via a survey from Canadian and Turkish university students using the convenience sampling method. A 2X4 MANOVA was used for analyzing the data. According to the results, individuals' cultural background and optimistic bias levels have no interaction effect on perceptual and behavioral gap when the product is hedonic. For functional products on the other hand, these two factors have a marginally significant interaction effect on the perceptual gap and a significant interaction effect on the behavioral gap. It is expected that the results obtained will contribute to the knowledge of researchers and practitioners who study the effects of media in the context of culture, advertisement, and consumer behavior.
\end{abstract}

\section{Keywords}

Third-person perception, Optimistic bias, Purchase intention, Suggestive advertising

\footnotetext{
* Bu çalışma 22. Pazarlama Kongresi'nde aynı yazarlarca sunulmuş olan bildirinin genişletilmiş ve güncellenmiş versiyonudur.

1 Sorumlu Yazar: Nezahat Ekici (Dr. Öğr. Üyesi), Karamanoğlu Mehmetbey Üniversitesi, İktisadi ve İdari Bilimler Fakültesi, Karaman, İşletme Bölümü, Karaman, Türkiye. E-posta: nezahatekici@kmu.edu.tr ORCID: 0000-0003-1697-3483

2 Bayram Zafer Erdoğan (Prof. Dr.), Anadolu Üniversitesi, İşletme Fakültesi, İşletme Bölümü, Eskişehir, Türkiye

E-posta: bzerdogan@anadolu.edu.tr ORCID: 0000-0002-2147-7356

Atıf: Ekici, N. ve Erdogan, B. Z. (2019). Reklamlarda üçüncü kişi algısının yanlı iyimserlik bağlamında değerlendirilmesi: Türkiye ve Kanada karşılaştirması. Istanbul Business Research, 48(2), 313-334. http://doi.org/10.26650/ibr.2019.48.0023
} 


\section{Extended Summary}

The third-person effect is defined as "people tend to believe that media messages have an influence on others more than themselves" (Davison, 1983). This definition points out a perceptual contradiction and consequently a perceptual gap about the media effects among individuals. The third-person effect has two components; perceptual and behavioral.

Optimistic bias theory argues that individuals believe that bad things happen more frequently to others compared to themselves (Chapin, 2013). Adapting this theory to media effects refers individuals' ego-centric behaviors when they make evaluations of any harmful or undesirable effects of media messages (Hullman, 2008). According to the literature, biased optimism may differ in a different culture.

The use of sex appeal has frequently used the method, but it is still argued how this kind of appeal is perceived by the targets or whether this perception causes any behavioral intention such as purchase intention. Additionally, many of the studies on third-person perception have focused on undesirable or anti-social messages (Paul et al., 2000; Perloff, 1999). Within the light of these studies, it can be inferred that individuals equate being affected by these messages as a negative life experience that they want to avoid. For that reason, organizing the reactions to such messages within the context of media effects is an important issue.

This study aims to examine individuals' possible reactions (effects on self and effects on others) to suggestive printed advertisements of different products by considering individuals' optimistic bias levels, in two different cultures. The main research question of this study is given as "Do the perceptual and behavioral gaps on functional and hedonic products differ depending on individuals' optimistic bias levels and cultural background?".

A factorial design was used. In an experimental setting, hypothetical print advertisements based on two different cultures (Canada and Turkey) and two different product types (perfume, hedonic and toothpaste, functional) were used. A survey was used to collect the data. University student samples were used in Canada and Turkey by using the convenience sampling method. To measure third-person perception, a scale adapted from Pan, Meng and Zhou (2012) was used. A score was calculated called the "perceptual gap". To calculate the score, the following formula was used - the score of influence on others minus the score of influence on the self. To measure purchase intention, a scale adapted from Shiv, Edell and Payne (1997) was used. The same procedure in measuring third-person perception was followed for this variable. A score was calculated called the "behavioral gap". To measure optimistic bias, a scale adapted from Gouveia and Clarke (2001) was used.

The median split method was used to determine categories based on individuals' optimistic bias levels. Individuals were categorized as relatively optimistic and relatively pessimistic. To find an answer to the main research question, 2X4 MANOVA was run. 
According to the results, individuals' cultural background and optimistic bias levels had no interaction effect on perceptual and behavioral gap when the product was hedonic $\left(F_{P G 1,796=}\right.$ $\left..187, p=.66, \eta^{2}=.072 ; F_{B G} 1,796=.054, p=.81, \eta^{2}=.056\right)$. For a functional product on the other hand, these two factors had a marginally significant interaction effect on the perceptual gap $\left(F_{1,796}=3.834 ; p=.05, \eta^{2}=.498\right)$ and a significant interaction effect on the behavioral gap $\left(F_{1,796}=3.902, p=.04, \eta^{2}=.505\right)$. Furthermore, when the effects of factors were examined separately, it was seen that individuals' cultural background had an effect on behavioral gap when the product was functional $\left(F_{1,796}=9.195, p=.03, \eta^{2}=.857\right)$. Also, it was seen that individuals' optimistic bias level had a marginally significant effect on behavioral gap when the product was functional $\left(F_{1,796}=3.539, p=.06, \eta^{2}=.968\right)$.

When the findings were evaluated in general, it is important that significant results were found for a functional product which is not considered directly related to sexuality. Perceptual gaps were closer to each other according to individuals' optimistic bias level in both cultures, but the perceptual gap in the functional product of relatively pessimistic Turks was greater than Canadians. The behavioral gap mean of Turks was higher than Canadians, but the mean of relatively optimistic Canadians was higher than relatively pessimistic Canadians. There were no big differences between Turks.

When the perceptual and behavioral gaps are compared, it is seen that the gap widens relatively when participants make a behavioral estimation such as purchase intention. Thus, individuals rate themselves as less and others as more when it comes to behavioral estimation. This result is relatively greater in hedonic products compared to functional ones. These results can be explained by the product category and whether individuals are part of an individualistic or collectivistic culture.

The effect of optimistic bias on self and other in both cultures is not seen clearly when the product is perfume which is considered directly related to sexuality, but it is seen when the product is toothpaste.

Abbreviations: PG: Perceptual Gap, BG: Behavioral Gap 


\section{Reklamlarda Üçüncü Kişi Algısının Yanlı İyimserlik Bağlamında Değerlendirilmesi: Türkiye ve Kanada Karşılaştırması}

Reklamcılıkta tüketicileri ikna etmek için korku, mizah, cinsellik, nadirlik vb. duygusal ve/ veya rasyonel çekicilikler yoğun olarak kullanılmaktadır (Clow ve Baack, 2005). Fakat bahsi geçen bu çekicilik unsurlarının kimin üzerinde, hangi durumlarda ve ne kadar etkili olabileceği alanyazında hala tartışılmaktadır. İlk kez 1983 yılında Davison tarafından ortaya atılan üçüncü kişi etkisi (third-person effect), "ikna edici bir iletişime maruz kalan hedef kitle üyelerinin, iletişimin diğerlerinde kendilerinden daha etkili olacağı beklentisidir (Davison, 1983)" şeklinde tanımlamıştır. Tanıma göre üçüncü kişi etkisi; bireylerin, kendileri ve diğerlerini kıyasladıklarında, diğer kişilerin medya mesajlarından daha çok etkilendiklerini ve bu mesajlara karşı daha duyarlı olduklarını algılamaları halinde söz konusudur (Davison, 1983; Gunther, 1995; Pan vd., 2012; Peiser ve Peter, 2001; Lambe ve McLeod, 2005; Huge vd., 2006; Sun vd., 2008b; Schmierbach vd., 2008). Üçüncü kişi etkisi teorisi medyanın insanların biliş ve davranışları üzerindeki etkilerine odaklanmanın ötesinde, bu algılanan etkilere verilen reaksiyonla ilgilenmektedir. Bu noktada medya mesajları, bireylere diğerlerinin ilişkisel varlığını dikkate alarak, diğerlerinin nasıl düşünebilecekleri ve buradan hareketle kendi davranışlarını düzenlemeleri için bir bağlam sağlamaktadır (Sun vd., 2008a, s. 281). Tanımdan da anlaşılacağ1 üzere, kendi ve diğerleri üzerinden yapılan değerlendirme, medya etkileri konusunda bireyler arasında algısal bir uyuşmazlığa ve dolayısıyla algısal bir boşluğa işaret etmektedir. Zira, üçüncü kişi etkisinin algısal ve davranışsal olmak üzere iki bileşeni vardır. Algısal bileşene yönelik çalışmalar şiddet içerikleri (Hoffner ve ark., 1999; McLeod, Eveland ve Nathanson, 1997), pornografi (Lee ve Tamborini, 2005 ; Lo ve ark., 2010), ticari reklam mesajları (Youn, Faber ve Shah, 2000; Wan , Faber ve Fung, 2003), reçeteli ilaç kullanımları için doğrudan tüketiciye yönelik reklamlar (Delorme, Huh ve Reid, 2006; Huh, Delorme ve Reid, 2004), politik reklamlar (Meirick, 2004; Paek ve ark., 2005) medyadaki cinsel mesajlar (Pan, Meng ve Zhou, 2012), gençlere yönelik filmlerde alkollü ürün yerleştirmeleri (Shin ve Kim, 2011), filmlerde cinsel içerik (Rosenthal vd., 2018) vb. konular üzerine, davranışsal bileşene yönelik çalışmaların ise sansür ve hükümetler tarafından yapılan bir takım düzenlemeler (Lee ve Tamborini, 2005; Salwen ve Dupagne, 1999; Youn, Wan ve Faber, 2001) üzerine yoğunlaştığ1 gözlenmiştir. Davranışsal bileşene yönelik akademik ilgi nispeten düşük görünmekle birlikte, son dönem çalışmalarda sansür dışındaki değişkenlere ilişkin değerlendirmelere rastlamak da mümkündür. Bunlar; reklamda bir cazibe unsuru olarak kıtlı̆̆ın kullanılması ve algılanan etkileri (Eisend 2008; Sharma ve Roy, 2016), bağış yapma niyeti (Kim, 2013), online pazarlama ve ağızdan ağıza iletişim (Zhang ve Daugherty, 2009), sosyal medya davranışı ve etkileri (Pham vd. 2019), online reklamlarla baş etme davranışı (Ham ve Nelson, 2016), ürün ya da markayı önerme istekliliği (Eisen, 2015) ve aldatıcı reklamlara karşı şüphecilik ve satın alma niyeti (Xie, 2016) vb. pazarlama iletişimi açısından kritik karar alanlarını etkileyen ve teorinin uygulama alanlarını genişletme çabası içinde olan araştırmalar olarak özetlenebilirler. 
Medya mesajının olumlu ya da olumsuz olması, arzulanabilir ya da istenilmeyen türden olması kendini güçlendirme ve benlik saygısıyla doğrudan bağlantılıdır. Reklamların ikna amacı ve bireylerde varolan medya etkilerine yönelik olumsuz tutum üçüncü kişi algısıyla ilişkilendirildiğinde (Huh vd., 2004), ticari reklamların etkisi altında olmanın dışarıdan çok zekice görünmüyor olması ve bu sebeple diğerlerinin bu tür içeriklerden daha fazla etkileneceği görüşünün hâkim olduğu (Eisend, 2008; Youn vd., 2000) açıklamasını yapmak mümkündür. Bu çalışmada cinsel içerikli reklamlar özelinde araştırma sorularına yanıt aranmıştır. Çünkü ilgili reklam mesajının arzulanabilirliği üçüncü kişi teorisi bakımından önemli bir değişkendir (Gunther ve Mundy, 1993; Peiser ve Peter, 2001). Ayrıca cinsel içerikli reklam alanyazını dikkate alındığında da reklama konu olan ürünün (Chang ve Tseng, 2013; Grazer ve Kissling, 1995; Reichert, Childers ve Reid, 2012) ve içerisinde yaşanılan kültürün (Ismail ve Melewar, 2014) reklamın algılanışı, reklam bilgisinin işlenmesi ve etkinliği üzerinde etkili olabileceğine yönelik sonuçlara ulaşılmıştır. Bu sebeple ilgili değiş̧kenler araştırma tasarımına dahil edilmiştir.

Yanlı iyimserlik teorisi (optimistic bias theory) ise bireylerin, kötü şeylerin daha çok diğerlerinin başına geleceği konusundaki inançlarını öngörür (Chapin, 2013, s. 394). Weinstein, bireylerin karşılaştırmalı risk değerlendirmeleri yaparken ben merkezci bir tutum takındıklarını ve diğer kişilerin kendilerine göre daha fazla risk altında olduğu kanısını taşımalarını yanlı iyimserlik olarak kavramsallaştırmıştır (Chapin, 2000, s. 322). Bu teorinin medya etkilerine uyarlanması ise, bireylerin bir uyaranın zararlı/istenmeyen etkilerini değerlendirirken kendi kendine hizmet eder şekilde yanlı davranmasını ifade eder (Hullman, 2008, s. 53). Bu durum yalnızca psikolojik bir eğilimi değil aynı zamanda davranışsal bir eğilimi de kapsar (Scheirer ve Carver, 1992). Gunther ve Mundy (1993) medya etkileri konusundaki algisal çelişkinin yanlı iyimserlikten kaynaklandığını ifade etmişlerdir. Teoriye göre tüm bireyler kendilerini diğerlerinden daha akıllı ve medya etkilerine karşı daha korunaklı şeklinde, üstün görme eğilimindedirler (Chia, Lu ve McLead., 2004, s. 111-113; Chia ve Wen, 2010, s. 543). Esasında bu tutum gerçekçi olmayan bir iyimserliğe işaret etmektedir (Labi ve Oliver, 2009, s. 101). Daha çok sosyal psikoloji ve özellikle sağlık alanyazını açısından önemli bir değişken olan yanlı iyimserlik, reçeteli ilaç reklamlarına yönelik tutumlar, reklamda şüphecilik, tüketicilerin bilgi arama ve işleme süreçleri ve tüketici niyetlerinin şekillenmesinde de etkili bir değişken olduğu ortaya konulmuş (Park vd., 2017) ve teorinin etki alanı genişletilmiştir. Weinstein (1989) yanlı iyimserliğin tüketicilerin önleyici ve iyileştirici davranışlar için niyetini azalttığını öne sürmektedir. Dolayısıyla özellikle reklamlardaki bilgilere, çekicilik unsurlarına vb. inanılıp inanılmaması noktasında bireysel farklılıkların önemini üçüncü kişi etkisi teorisi bağlamında yanlı iyimserlik perspektifinden ele almak alanyazına önemli bir katkı sunabilecektir. Alanyazına göre yanlı iyimserlik içinde yaşanılan kültüre göre farklı şekillerde tezahür etmektedir (Ji vd., 2004; Heine ve Lehman, 1995). Heine ve Lehman (1995) bireyci (Kanada) ve kolektivist (Japonya) iki kültürde bireylerin pozitif ve negatif olaylara 
yönelik kişisel risk algılarını karşılaştırmışlar ve bireyci bir toplumun parçası olan kişilerin kolektivist bir toplumun parçası olanlara nazaran daha yanlı iyimser oldukları sonucuna ulaşmışlardır. Dolayısıyla yanlı iyimserlik konusunda kültürel farklılıklar olmakla birlikte, Kuzey Amerikalılarda yanlı iyimserlik düzeyi nispeten yüksektir sonucuna ulaşmışlardır. Yine Kitayama ve arkadaşlarına (1997) göre Doğulu toplumlardaki bağımlı benlik yapısı daha çok ait olma duygusuyla ilgilidir. Zira kendisini diğerlerinden üstün bir şekilde değerlendirme eğilimi ve kişisel başarı motivasyonları Batılı toplumlara atfedilen kendini güçlendirme (self-enhancement) ile ilintilidir. Aksine Doğulular, diğerleriyle uyumu sürdürmek ve sağlamak adına kendilerini diğerleriyle eşit/benzer gören, kendi kendini eleştirebilen ve belki karşılaştırma yaptıkları gruba daha fazla odaklanan bir profil sergileyebilirler (Rose, Endo ve Windschitl, 2008:1237). Yine Heine ve Lehman (1995) başlarına gelen ya da gelecek olan olaylar konusunda her bir kültürün aynı oranda kişisel sorumluluk almadığını, kültürden kültüre bu davranışın değişebildiğini ifade etmişlerdir. Örneğin Amerikan kültüründe insanlar başlarına gelebilecek olayları kontrol edebildiklerini düşünmekte ve olan herhangi bir şeyde sorumlulukları olduğuna inanmaktadırlar. Chang, Asakawa ve Sanna (2001) da Batılı kültürlerin olumlu ya da olumsuz farketmeksizin gelecek yaşam beklentisiyle ilgili olaylara karşı önyargılı iyimser, Doğulu kültürlerin ise kötümser olduklarını ifade etmişlerdir. Öte yandan Fontaine ve Smith (1995) sağlikla ilgili gelecek tahminlemelerinde kültürlerarası farkların hassasiyet farklılıklarından kaynaklanabileceği, bunun da maruz kalma sıklığının (örneğin medyada) bir sonucu olabileceğinden bahsetmişlerdir. O sebeple, bu çalışmadaki cinsel içerikli reklamlar ve bu reklamlara yönelik üçüncü kişi algısının bireylerin iyimserlik düzeylerine göre değerlendirilmesi noktasında da sonuçlar değerlendirilirken her iki kültürün kişisel sorumluluk düzeyleri, ilgili mesajın arzulanırlık düzeyi ve bahsi geçen içeriklere maruz kalma sıklıkları gibi motivasyonel ve bilişsel açıklamalar (Shen vd., 2010) dikkate alınması gereken hususlardır.

Üçüncü kişi algısını etkileyen ya da açıklayan faktörlerle ilgili sistematik ve tutarlı bir teorik çerçeve hala ortaya koyulamamış olmakla birlikte (Shen vd., 2018, s.400), üçüncü kişi algısı ve yanlı iyimserlik üzerine yapılan çalışmalarda iki değişkenin aynı mekanizmalar tarafından açıklanıp açıklanmadığı (Salwen ve Dupagne, 2003; Wei, Hwei ve Lu, 2007) ve yanlı iyimserliğin üçüncü kişi algısını açıklayan değişkenlerden birisi olup olmadığı (Chapin, 2008) vb. üzerine çalışmalara rastlamak mümkündür.

Sonuç olarak, reklamda cinsel çekicilik kullanımı sıklıkla başvurulan bir yöntem olmakla birlikte, bu tür çekicilik unsurlarının hedef kitlesi tarafindan nasıl algılandığı ya da bu alg1nın satın alma vb. davranışsal bir niyete dönüşüp dönüşmediği hala tartışlan bir konudur. Ayrıca üçüncü kişi etkisi üzerine yapılmış pek çok çalışmada istenmeyen ya da doğası gereği sosyal olarak arzulanmayan mesajlara odaklanılmıştır (Paul, Salwen ve Dupagne, 2000; Perloff, 1999). Bireyler ise bu tarz mesajlardan etkilenmiş olmayı kaçınmak isteyecekleri negatif bir yaşam deneyimi olarak değerlendirebilmektedirler. Dolayısıyla ilgili reklamlara yönelik 
tüketici tepkilerinin medya etkileri bağlamında organize edilmesi önemli bir husustur. $\mathrm{Bu}$ sebeple bu çalı̧̧mayla iki farklı kültürlerdeki bireylerin yanlı iyimserlik düzeyleri dikkate alınarak (nispeten iyimser ve nispeten kötümser) farklı ürünlerin cinsel içerikli basılı reklamlarına karşı kendilerinin ve diğerlerinin muhtemel etkilenimleri (algısal bileşen) ve satın alma niyetlerinin (davranışsal bileşen) sorgulanması amaçlanmıştır.

Bu çalışmanın temel araştırma sorusu; "faydacı ve hedonik ürün reklamlarında gözlenen üçüncü kişi etkisi bireylerin yanlı iyimserlik düzeyleri ve kültürel geçmişlerine göre farklılaşmakta mıdır?" şeklinde ifade edilmiştir. Ürün gruplarına bağlı olarak bir değerlendirme yapılmasında, reklam mesajındaki çekicilik unsurunun (cinsellik) ürünle uyumlu/uyumsuz değerlendirilmesi hususunun etkili bir faktör olacağ d düşünülmüştür.

Çalışma farklı kültürel örüntüler ve tüketim kalıplarına sahip iki toplumun cinsel içerikli reklamlara yönelik algısal ve davranışsal tutumlarını psikolojik birtakım değişkenleri dikkate alarak karşılaştırması bakımından önemlidir. Ayrıca çalışmanın, üçüncü kişi etkisi teorisi bağlamında öncü çalışma olması niteliğiyle de ulusal alanyazında bir boşluğu doldurması beklenmektedir.

\section{Yöntem}

$\mathrm{Bu}$ araştırmada iki veya daha fazla değişkenin etkilerinin test edildiği faktöriyel tasarım kullanılmıştır. Bu amaçla iki farklı kültür (Türkiye ve Kanada) ve iki farklı ürün kategorisi (hedonik -parfüm- ve faydacı -diş macunu-) temel alınarak basılı hipotetik dergi reklamlarından faydalanılmıştır. Deneysel düzen ürün kategorisi denekler içinde olacak şekilde tasarlanmıştır. Çalışma kapsamında Türkiye ve Kanada örnekleminin seçilmesinde, farklı kültürel geçmişlere ve farklı tüketim değerlerine sahip iki toplum olması (Waller vd, 2013) belirleyici olmuştur. Türk toplumu kolektivist bir toplulukken (Bkz:Hofstede (2001)'e göre Türkiye'nin bireycilik skoru: 37), Kanada ise bireyci bir topluluk olarak (Bkz:Hofstede (2001)'e göre Kanada'nın bireycilik skoru: 80) dikkate alınmıştır.

\section{Örneklem ve Katılımcılar}

Araştırma kapsamında Türkiye'de $\left(n=400 ; n_{\text {erkek }}=200 ; n_{\text {kadin }}=200\right)$ ve Kanada'da ( $n$ $=400 ; n_{\text {erkek }}=200 ; n_{\text {kadin }}=200$ ) ilgili üniversitelerin İşletme Fakültesi öğrencilerinden kolayda örnekleme yoluyla veri toplanmıştır. Araştırmada her iki ülkedeki katılımcı sayılarının ve cinsiyet dağılımlarının eşit olmasına dikkat edilmiştir. Her iki üniversite için de gerekli etik izinler alınmış, veri toplama sırasında gönüllü katılım prosedürleri izlenmiş ve veri toplama sonrasında katılımcılarla geri bilgilendirme (debrifing) formu paylaşılmıştır. Veriler sınıf içi ortamda toplanmış olup, katılımcılar arası etkileşim mümkün olduğunca engellenmiştir. Araştırmaya katılım ön çalışmalarda pizza partisi ve çikolata ile, nihai araştırmaya katılım ise vize sınavında ekstra not önerisiyle teşvik edilmiştir. 


\section{Veri Toplama Araçları}

Çalışmada çoklu veri toplama stratejilerini kapsayan ve bir bakıma kalitatif ve kantitatifin evliliği olarak (Erdoğan, 2000) değerlendirilen yöntemsel (methodological) üçleme benimsenmiş olup, veri setleri görüşmeler, gözlemler ve anket verileri vb. çeşitlenmiştir.

İlk olarak, her iki kültürde de hedonik ve faydacı ürün gruplarını belirlemek amacıyla iki farklı ön çalışma yürütülmüştür. Yapılandırılmış anket formları aracılığıyla kolayda örnekleme yöntemiyle öğrenci örnekleminden toplanan veriler analiz edilmiş ve hedonik ürün olarak parfüm, faydacı ürün olarak ise diş macunu belirlenmiştir. Ürünlerin hedonik mi yoksa faydacı olarak mı algılandıklarını kontrol etmek amacıyla Coelho do Vale ve Duarte (2013)'den uyarlanan ölçek ${ }^{1}$ kullanılmıştır. Sonuçlar tablo 1'de paylaşılmıştır.

Tablo 1

Faydacı ve Hedonik Algllanma Derecelerine Göre Ürünler

\begin{tabular}{lccc}
\hline Ürün & Ortalama* $^{*}$ & N & \\
\hline Diş Macunu & 1,96 & 103 & 1. Faydac1 \\
Kot Pantolon & 4,40 & 103 & \\
Flash Disk & 2,50 & 103 & 2. Faydac1 \\
Parfüm & 5,04 & 103 & 1. Hedonik \\
Makarna & 2,59 & 103 & \\
Çikolata & 4,69 & 103 & 2. Hedonik \\
Bisküvi & 4,10 & 103 & \\
Güneş Gözlüğü & 4,28 & 103 & \\
\hline
\end{tabular}

* 1: Çok faydacı - 7: Çok hedonik

Sonuçlara göre parfüm ve çikolata hedonik ürün olarak, diş macunu ve flash disk ise faydacı ürün olarak ön plana çıkmıştır. Bu ürünlerin faydacı ve hedonik boyutlarını kontrol etmek amaciyla 12 faydacı ve 12 hedonik sıfattan oluşan ve Spangenberg vd. (1997)’ den uyarlanan semantik farklılık ölçeği kullanılarak tekrar bir sağlama yapılmıştır. Açımlayıcı Faktör Analizi sonrası hedonik ürünler için hedonik boyutların, faydacı ürünler için faydacı boyutların ortalama karşılaştırması gerçekleştirilmiştir. Sonuçlar Tablo 2'de paylaşılmıştır.

Tablo 2

Belirlenen Ürünler Iç̧in Hedonik ve Faydacı Boyut Ortalama Karşılaştırılması

\begin{tabular}{lccccc}
\hline & Ortalama & S.S & df & t & P \\
\hline Parfüm & 3.69 & 1.16 & \multirow{2}{*}{160} & 4.038 & $0.001^{*}$ \\
Çikolata & 3.26 & 1.41 & & & 2.140 \\
Diş Macunu & 1.52 & 0.63 & 160 & $0.034^{*}$ \\
Flash Disk & 1.43 & 0.68 & & & \\
\hline
\end{tabular}

$* \mathrm{p}<.05$

Test sonuçlarına göre ortalama farklılıkları anlamlı çıkmıştır. Bu sonuçlardan hareketle hedonik ürün olarak parfüm, faydacı ürün olarak ise diş macunu belirlenmiştir. Test sonuçla- 
rına göre çok az bir farkla flash disk daha faydacı olarak değerlendirilmektedir ancak burada iki ürün grubunun birbiriyle uyumlu olma durumları vb. bir takım değişkenler dikkate alınarak yargısal bir kararla diş macunu seçilmiştir.

Ardından, ölçmede kullanılacak olan hipotetik reklamların ekolojik geçerliğini sağlamak amacıyla da her iki kültürde üç farklı grupla - yalnızca kadınlar, yalnızca erkekler ve karma grup- olmak üzere toplamda 6 farklı odak grup görüşmeleri gerçekleştirilmiştir. Odak grup katılımcılarına bir reklamı cinsel içerikli olarak değerlendirmeleri için ne tür işaretler aradıkları sorusu yöneltilmiş ve cinsel içerikli olarak tanımladıkları reklam için aşağıdaki değerlendirmeleri (Pan, Meng ve Zhou, 2012' den uyarlanmıştır) yapmaları istenmiştir.

- Reklamların herhangi bir cinsel içerik (görsel, kelime, imaj vb.) içerip içermediği,

- Bu içeriğin ne kadar belirgin olduğu,

- Bu içeriğin ne kadar gerçekçi ve güçlü olduğu,

- Reklamların izleyiciyi seks üzerine düşünmeye sevk edip etmediği,

- Reklamdaki cinsel içeriğin(varsa) ürün grubu dikkate alındığında gerekli olup olmadığı.

- Reklamdaki cinsel içeriğin (varsa) kabul edilebilir düzeyde olup olmadığı,

- Reklamdaki cinsel içeriğin (varsa) satın almaya sevk edip etmediği gibi sorular yöneltilmiştir.

Bu sayede, hem araştırıcı tarafından daha önce keşfedilmemiş ya da tanımlanmamış bilgilere ulaşılabilmesi hem de araştırmanın alan deneyi aşamasında kullanılacak olan reklamların sağlıklı bir şekilde belirlenmesi amacıyla kontrollerin yapılmış olması sağlanmıştır.

Araştırmada A4 renkli kuşe kâğıda kitapçık formatında bir anket formu kullanılmıştır. Bu kitapçıkta iki farklı ürüne ait birer adet tam sayfa reklam ile araştırmada ölçülmeye çalışılan değişkenlere ilişkin ifadeler yer almıştır.

\section{Üçüncü Kişi Algısı Ölçeği}

Üçüncü kişi algısı ölçeği Pan, Meng ve Zhou (2012) ‘in çalışmasından uyarlanmıştır. Ölçekte katılımcılar iki farklı ifade setine maruz kalmışlardır. Katılımcılar ilgili ifadeleri önce kendilerini daha sonra da diğerlerini dikkate alarak yanıtlamışlardır. Bu çalışmada "diğerleri" "üniversitenizde eğitim görmekte olan diğer öğrenciler” olarak tanımlanmıştır. Ölçek ifadelerinin puanlamas1 "1" (kesinlikle katılmıyorum) ile "5" (kesinlikle katıllyorum) arasında derecelendirilmiştir. Ölçeğin Türkçe’ye uyarlanması çeviri ve geri çeviri yöntemi kullanılarak iki çevirmen tarafından yapılmıştır. 
İlgili alanyazın dikkate alınarak bu çalışmada kendi ve diğerleri şeklinde yapılan ölçüm üçüncü kişi algısı için "algılanan boşluk” olarak skora dönüştürülmüştür. Bu skorun hesaplanmasında temel mantık, cinsel içerikli reklamın diğerleri üzerindeki muhtemel etkisinden kendi üzerindeki muhtemel etkinin çıkarılmasına dayanmaktadır.

Bu çalışma kapsamında ölçeğin geçerlik ve güvenirliğine ilişkin gerçekleştirilen analiz sonuçları ürün gruplarına göre Tablo 3 ve Tablo 4'de paylaşılmıştır.

Tablo 3

Hedonik Üründe Üçüncü Kişi Algısı Ölçeği İçin Tanımlayıcı İstatistikler ve Faktör Analizi

\begin{tabular}{|c|c|c|c|c|c|c|c|}
\hline \multicolumn{3}{|c|}{ Türkiye } & \multicolumn{2}{|r|}{ Ölçek } & \multicolumn{3}{|c|}{ Kanada } \\
\hline & $\begin{array}{l}\text { Faktör } \\
\text { Yükü }\end{array}$ & Ort. & S.S. & Üçüncü Kişi Algısı & $\begin{array}{l}\text { Faktör } \\
\text { Yükü }\end{array}$ & Ort. & S.S. \\
\hline \multirow{3}{*}{$\underset{z}{\tilde{0}}$} & .711 & 2.03 & 1.057 & Reklamı yapılan ürünü kullanmak isterim. & .535 & 2.03 & 1.129 \\
\hline & .958 & 2.62 & 1.269 & $\begin{array}{l}\text { Bu reklam, reklamı yapılan ürünü benim } \\
\text { için hatırlanabilir kılar. }\end{array}$ & .940 & 2.59 & 1.281 \\
\hline & .716 & 2.87 & 11.323 & $\begin{array}{l}\text { Reklamı yapılan ürünün cinsel cazibemi } \\
\text { artıracağına inanırım. }\end{array}$ & .773 & 2.37 & 1.240 \\
\hline \multirow{3}{*}{$\frac{\overrightarrow{0}}{\overline{0}}$} & .771 & 3.12 & 1.088 & Reklamı yapılan ürünü kullanmak isterler. & .705 & 2.98 & 1.001 \\
\hline & .968 & 3.49 & 1.041 & $\begin{array}{l}\text { Bu reklam, reklamı yapılan ürünü onlar için } \\
\text { hatırlanabilir kılar. }\end{array}$ & .847 & 3.38 & 1.053 \\
\hline & .758 & 3.47 & 1.101 & $\begin{array}{l}\text { Reklamı yapılan ürünün cinsel cazibelerini } \\
\text { artıracağına inanırlar. }\end{array}$ & .864 & 3.17 & 1.025 \\
\hline
\end{tabular}

\section{(Kendi - TR)}

Cronbach Alpha $=.831$

Özdeğer: 2.2

Açıklanan Varyans : \% 75.1

KMO Test: .674

Barlett Test : $\chi 2=503.820, p=.0001$

(Diğerleri - TR)

Cronbach Alpha $=.868$

Özdeğer: 2.3

Açılkanan Varyans : \% 79.3

KMO Test: .691

Barlett Test : $\chi 2=633.901, p=.0001$

\author{
(Kendi - CA) \\ Cronbach Alpha= 0,787 \\ Özdeğer: 2,1 \\ Açıklanan Varyans : \% 70,2 \\ KMO Test: .636 \\ Barlett Test : $\chi 2=416.474, p=.0001$ \\ (Diğerleri - CA) \\ Cronbach Alpha $=.846$ \\ Özdeğer: 2.2 \\ Açıklanan Varyans : \% 76.4 \\ KMO Test : .711 \\ Barlett Test : $\chi 2=521.417, \mathrm{p}=.0001$
}

İlk olarak faktör analizi gerçekleştirilmiş ve faktör üretme yöntemi olarak (extraction method) en büyük olabilirlik (methods of maximum likelihood) ve döndürme yöntemi (rotation method) olarak da promax metot kullanılmıştır. Güvenirlik analizi için de Cronbach Alfa katsayısı dikkate alınmıştır. Üçüncü kişi algısı beklendiği üzere tek faktörle açıklanmış olup, $\mathrm{KMO}$ ve p değerleri dikkate alındığında ölçeğin güvenirlik analizine uygun olduğu ve alpha katsayısının eşik değer olan .70 den büyük olduğu gözlenmiştir. 
Tablo 4

Faydacı Üründe Üçüncü Kişi Algısı Ölçeği İçin Tanımlayıcı İstatistikler ve Faktör Analizi

\begin{tabular}{|c|c|c|c|c|c|c|c|}
\hline & \multicolumn{3}{|c|}{ Türkiye } & \multirow{2}{*}{$\begin{array}{l}\text { Ölçek } \\
\text { Üçüncü Kişi Algısı }\end{array}$} & \multicolumn{3}{|c|}{ Kanada } \\
\hline & $\begin{array}{l}\text { Faktör } \\
\text { Yükü }\end{array}$ & Ort. & S.S & & $\begin{array}{l}\text { Faktör } \\
\text { Yükü }\end{array}$ & Ort. & S.S \\
\hline \multirow{3}{*}{ := } & .653 & 1.77 & .982 & Reklamı yapılan ürünü kullanmak isterim. & .450 & 2.06 & 1.149 \\
\hline & .961 & 2.32 & 1.257 & $\begin{array}{l}\text { Bu reklam, reklamı yapılan ürünü benim için } \\
\text { hatırlanabilir kılar. }\end{array}$ & .964 & 2.64 & 1.327 \\
\hline & 676 & 2.66 & 1.359 & $\begin{array}{l}\text { Reklamı yapılan ürünün cinsel cazibemi artıracağına } \\
\text { inanırım }\end{array}$ & .728 & 2.43 & 1.271 \\
\hline \multirow{3}{*}{$\frac{\overrightarrow{\bar{\theta}}}{\dot{\bar{\Delta}}}$} & 688 & 2.69 & 1.099 & Reklamı yapılan ürünü kullanmak isterler. & .465 & 2.63 & .980 \\
\hline & .904 & 3.26 & 1.121 & $\begin{array}{l}\text { Bu reklam, reklamı yapılan ürünü onlar için } \\
\text { hatırlanabilir kılar. }\end{array}$ & .911 & 3.31 & 1.059 \\
\hline & .835 & 3.19 & 1.164 & $\begin{array}{l}\text { Reklamı yapılan ürünün cinsel cazibelerini } \\
\text { artıracağına inanırlar. }\end{array}$ & .727 & 3.13 & 1.023 \\
\hline
\end{tabular}

\section{(Kendi - TR)}

Cronbach Alpha $=.794$

Özdeğer: 2.1

Açıklanan Varyans : \% 71.6

KMO Test : .653

Barlett Test : $\chi 2=417.670 \mathrm{p}=.0001$

(Diğerleri - TR)

Cronbach Alpha $=.848$

Özdeğer: 2.3

Açıklanan Varyans : \% 76.8

KMO Test : .701

Barlett Test : $\chi 2=546.397 \mathrm{p}=.0001$

\author{
(Kendi - CA) \\ Cronbach Alpha $=.746$ \\ Özdeğer: 1.9 \\ Açıllanan Varyans : \% 66.4 \\ KMO Test: .600 \\ Barlett Test : $\chi 2=352.026, p=.0001$ \\ (Diğerleri - CA) \\ Cronbach Alpha= ,733 \\ Özdeğer: 1,9 \\ Açıllanan Varyans : \% 65.4 \\ KMO Test : .615 \\ Barlett Test : $\chi 2=310.495, \mathrm{p}=.0001$
}

\section{Satın Alma Niyeti Ölçeği}

Satın alma niyeti ölçeği Shiv, Edell ve Payne (1997)' in çalışmasından uyarlanmıştır. Ölçekte katılımcılar iki farklı ifade setine maruz kalmışlardır. Katılımcılar ilgili ifadeleri önce kendilerini daha sonra da diğerlerini dikkate alarak yanıtlamışlardır. Bu çalışmada "diğerleri" üniversitenizde eğitim görmekte olan diğer öğrenciler olarak tanımlanmıştır. Ölçek ifadelerinin puanlaması "1" (kesinlikle katılmıyorum) ile "5" (kesinlikle katıllyorum) arasında derecelendirilmiştir. Ölçeğin Türkçe’ye uyarlanması çeviri ve geri çeviri yöntemi kullanılarak iki çevirmen tarafından yapılmıştır.

İlgili alanyazın dikkate alınarak bu çalışmada kendi ve diğerleri şeklinde yapılan ölçüm satın alma niyeti için "davranışsal boşluk" olarak skora dönüştürülmüştür. Bu skorun hesaplanmasında temel mantık, cinsel içerikli reklamın diğerlerinin satın alma niyeti üzerindeki muhtemel etkisinden kendi üzerindeki muhtemel etkinin çıkarılmasına dayanmaktadır.

$\mathrm{Bu}$ çalışma kapsamında ölçeğin geçerlik ve güvenirliğine ilişkin gerçekleştirilen analiz sonuçları ürün gruplarına göre Tablo 5 ve Tablo 6'de paylaşılmıştır. 
Tablo 5 .

Hedonik Üründe Satın Alma Niyeti Ölçeği Iç̧in Tanımlayıcı İstatistikler ve Faktör Analizi

\begin{tabular}{|c|c|c|c|c|c|c|c|}
\hline & \multicolumn{3}{|c|}{ Türkiye } & \multirow{2}{*}{$\begin{array}{l}\text { Ölçek } \\
\text { Satın Alma Niyeti }\end{array}$} & \multicolumn{3}{|c|}{ Kanada } \\
\hline & $\begin{array}{l}\text { Faktör } \\
\text { Yükü }\end{array}$ & Ort. & S.S & & $\begin{array}{l}\text { Faktör } \\
\text { Yükü }\end{array}$ & Ort. & S.S \\
\hline \multirow{3}{*}{$\underset{\bar{D}}{\ddot{D}}$} & .915 & 1.80 & 1.003 & $\begin{array}{l}\text { Reklamı yapılan ürünü kullanmayı kesinlikle } \\
\text { deneyeceğim. }\end{array}$ & .825 & 1.71 & .947 \\
\hline & .934 & 1.72 & .967 & $\begin{array}{l}\text { Reklamı yapılan ürünü büyük ihtimalle } \\
\text { alacağım. }\end{array}$ & .926 & 1.63 & .939 \\
\hline & .790 & 2.02 & 1.187 & $\begin{array}{l}\text { Ürüne ihtiyaç duyduğumda reklamı yapılan } \\
\text { ürünü satın alacağım. }\end{array}$ & .883 & 1.63 & .969 \\
\hline \multirow{3}{*}{ 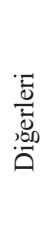 } & .932 & 2.96 & 1.086 & $\begin{array}{l}\text { Reklamı yapılan ürünü kullanmayı kesinlikle } \\
\text { deneyeceklerdir. }\end{array}$ & .847 & 2.80 & 1.031 \\
\hline & .929 & 2.93 & 1.133 & $\begin{array}{l}\text { Reklamı yapılan ürünü büyük ihtimalle } \\
\text { alacaklardır. }\end{array}$ & .929 & 2.70 & 1.041 \\
\hline & .826 & 3.10 & 1.147 & $\begin{array}{l}\text { Ürüne ihtiyaç duyduklarında reklamı yapılan } \\
\text { ürünü satın alacaklardır. }\end{array}$ & .876 & 2.69 & 1.045 \\
\hline
\end{tabular}

\section{(Kendi - TR)}

Cronbach Alpha $=.903$

Özdeğer: 2.5

Açıklanan Varyans : \% 84.8

KMO Test : .733

Barlett Test : $\chi 2=860.738, \mathrm{p}=.0001$

(Diğerleri - TR)

Cronbach Alpha $=.923$

Özdeğer: 2.6

Açılklanan Varyans : \% 86.7

KMO Test : .746

Barlett Test : $\chi 2=947.893, \mathrm{p}=.0001$

\author{
(Kendi - CA) \\ Cronbach Alpha $=.909$ \\ Özdeğer: 2.5 \\ Açıllanan Varyans : \% 84.6 \\ KMO Test: .745 \\ Barlett Test : $\chi 2=817.680, \mathrm{p}=.0001$ \\ (Diğerleri - CA) \\ Cronbach Alpha $=.914$ \\ Özdeğer: 2.5 \\ Açılklanan Varyans : \% 85.3 \\ KMO Test : .750 \\ Barlett Test : $\chi 2=846.971, \mathrm{p}=.0001$
}

Sonuç olarak, satın alma niyeti tek faktörle açıklanmış olup, KMO ve p değerleri dikkate alındığında ölçeğin güvenirlik analizine uygun olduğu ve alpha katsayısının eşik değer olan .70 den büyük olduğu gözlenmiştir.

Tablo 6

Faydacı Üründe Satın Alma Niyeti Ölçeği İçin Tanımlayıcı Ístatistikler ve Faktör Analizi

\begin{tabular}{|c|c|c|c|c|c|c|c|}
\hline & \multicolumn{3}{|c|}{ Türkiye } & \multirow{2}{*}{$\begin{array}{l}\text { Ölçek } \\
\text { Satın Alma Niyeti }\end{array}$} & \multicolumn{3}{|c|}{ Kanada } \\
\hline & $\begin{array}{l}\text { Faktör } \\
\text { Yükü }\end{array}$ & Ort. & S.S & & $\begin{array}{l}\text { Faktör } \\
\text { Yükü }\end{array}$ & Ort. & S.S \\
\hline \multirow{3}{*}{ 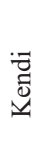 } & .902 & 1.60 & .858 & Reklamı yapılan ürünü kullanmayı kesinlikle deneyeceğim. & .774 & 1.64 &. .852 \\
\hline & .935 & 1.56 & .850 & Reklamı yapılan ürünü büyük ihtimalle alacağım. & .926 & 1.59 &. .886 \\
\hline & .786 & 1.83 & 1.092 & $\begin{array}{l}\text { Ürüne ihtiyaç duyduğumda reklamı yapılan ürünü satın } \\
\text { alacağım. }\end{array}$ & .875 & 1.59 &. .932 \\
\hline
\end{tabular}




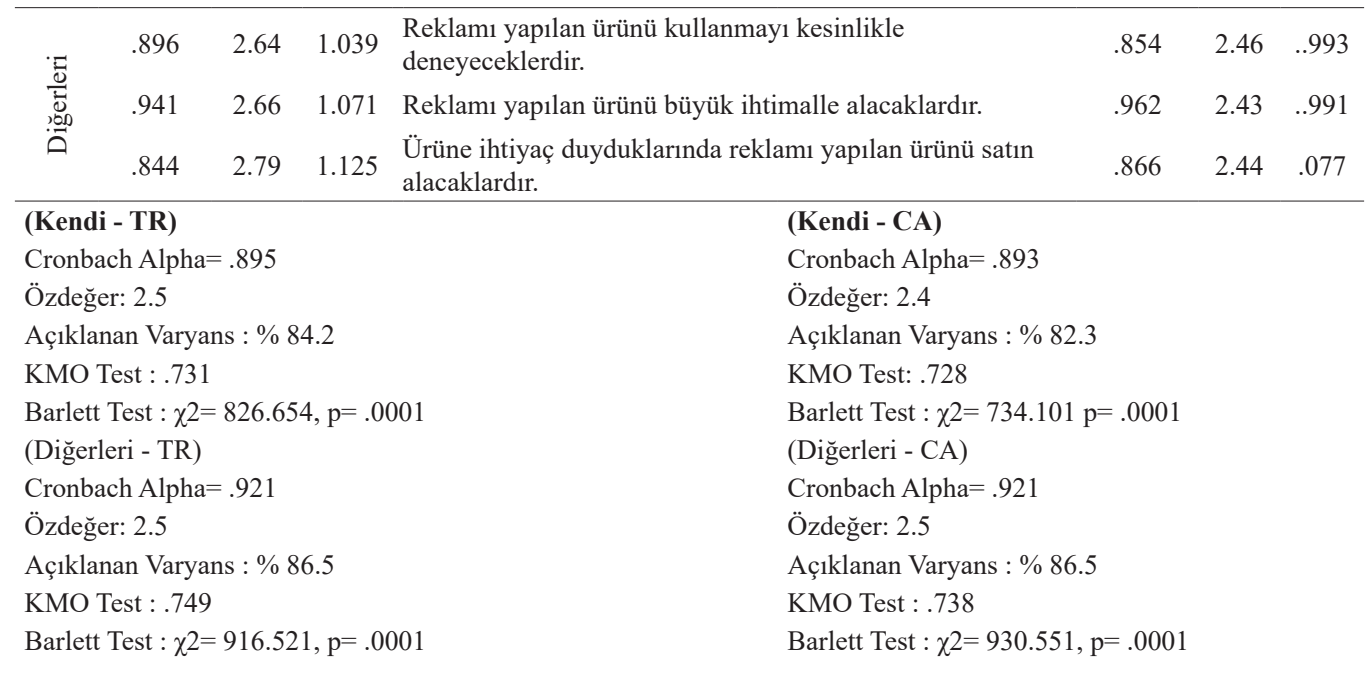

\section{Yanlı İyimserlik Ölçeği}

Yanlı iyimserlik ölçeği ise Gouveia ve Clarke (2001) 'ın çalışmasından uyarlanmıştır. Yanlı iyimserlik ölçeğinde üç olumlu ve üç olumsuz gelecek yaşam beklentisi sunulmuş ve katılımcıdan üniversitesindeki diğer öğrencileri dikkate alarak (doğrudan ölçüm) bu altı olayın kendi başına gelmesi olasılı̆̆ını değerlendirmesi (kişisel risk tahminlemesi) istenmiştir. $\mathrm{Bu}$ ölçekte yer alan ters kodlu (olumsuz) ifadeler analiz aşamasında düzeltilmiştir. Ölçek ifadelerinin puanlanması "1" (çok düşük) ile "5" (çok yüksek) arasında derecelendirilmiştir. Ölçeğin Türkçe'ye uyarlanması çeviri ve geri çeviri yöntemi kullanılarak iki çevirmen tarafindan yapılmıştır.

$\mathrm{Bu}$ çalışma kapsamında ölçeğin geçerlik ve güvenirliğine ilişkin gerçekleştirilen analiz sonuçları Tablo 7'de paylaşılmıştır.

Tablo 7

Yanlı Iyimserlik Ölçeği Için Tanımlayıcı Ístatistikler ve Faktör Analizi

\begin{tabular}{|c|c|c|c|c|c|c|c|}
\hline & & \multicolumn{3}{|c|}{ Türkiye } & \multicolumn{3}{|c|}{ Kanada } \\
\hline & & $\begin{array}{l}\text { Faktör } \\
\text { Yükü }\end{array}$ & Ort. & S.S & $\begin{array}{l}\text { Faktör } \\
\text { Yükü }\end{array}$ & Ort. & S.S \\
\hline \multirow{3}{*}{ 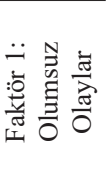 } & Felç geçirme olasılığım* & .785 & 2.13 & .952 & .674 & 1.90 & 1.008 \\
\hline & $\begin{array}{l}\text { HIV virüsüne yakalanma } \\
\text { olasıllı̆̆ı** }\end{array}$ & .740 & 1.87 & .953 & .715 & 1.52 & .903 \\
\hline & $\begin{array}{l}\text { Cilt kanserine yakalanma } \\
\text { olasılığım.* }\end{array}$ & .746 & 2.49 & .915 & .805 & 2.54 & 1.152 \\
\hline
\end{tabular}




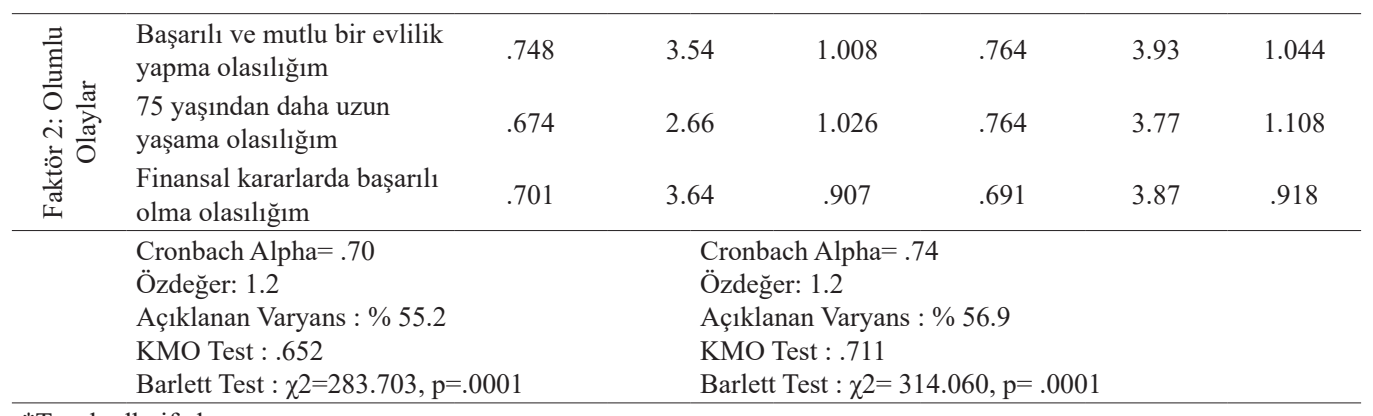

*Ters kodlu ifade

Buna göre, yanlı iyimserlik iki faktörle açıklanmış olup, KMO ve p değerleri dikkate alındığında ölçeğin güvenirlik analizine uygun olduğu ve alpha katsayısının eşik değer olan .70 den büyük olduğu gözlenmiştir.

\section{İșlem}

Verilerin analizinde SPSS 20.0 paket programı kullanılmıştır. Bireylerin yanlı iyimserlik düzeylerini kategorik olarak belirlemek amacıyla medyan split yöntemine başvurulmuş ve gruplandırmada kullanılan medyan değeri Türk katılımcılar için 3.5, Kanadalı katılımcılar için ise 4.0 olarak belirlenmiştir. Bireyler nispeten iyimser ${ }^{2}\left(n_{C A}=222 ; n_{T R}=232\right)$ ve nispeten kötümser ${ }^{3}\left(n_{C A}=178 ; n_{T R}=168\right)$ olmak üzere gruplandırılmıştır.

Araştırma sorusuna yanıt bulmak amacıyla 4 bağımlı (hedonik üründe algısal boşluk, faydacı üründe algısal boşluk, hedonik üründe davranışsal boşluk, faydacı üründe davranışsal boşluk) 2 bağımsız (kültür ve yanlı iyimserlik düzeyi) değişkenle MANOVA (Çok Değişkenli Varyans Analizi) gerçekleştirilmiştir. Çalışmada kültür ve yanlı iyimserlik değişkenleri için olmak üzere ana etkileri ve ortak etkileri ortaya koymaya yönelik analizler yapılmış olup, anlamlı sonuçlar için de izleme analizlerine başvurulmuştur. MANOVA öncesi varyans-kovaryans matrislerinin homojenliği sorgulanmış, Box-M istatistik değerinin anlamlı olmadığ1 $(.054>.05)$ görülmüştür.

“Bireylerin kültürel geçmişi ve yanll iyimserlik düzeyleri üçüncü kişi etkisi (algisal ve davranışsal boşluk) üzerinde birlikte bir etkiye sahiptir " hipotezi iki farklı ürün grubu için ayrı ayrı test edilmiş ve analiz sonuçları izleyen bölümde paylaşılmıştır.

\section{Bulgular}

Elde edilen sonuçlara göre ürün hedonik olduğunda katılımcıların kültürel geçmişi ve

2 Bahsi geçen olayların diğerlerine kıyasla kendi başına gelme ihtimalini yüksek gören

3 Bahsi geçen olayların diğerlerine kıyasla kendi başına gelme ihtimalini düşük gören 
yanlı iyimserlik düzeyleri algısal ve davranışsal boşluk üzerinde birlikte bir etkiye sahip değildir $\left(F_{A B}{ }^{4} 1,796=.187, p=.66, \eta^{2}=.072 ; F_{D B}{ }^{5} 1,796=.054, p=.81, \eta^{2}=.056\right)$. Bu noktada reklama konu olan ürün kategorisinin önemli bir bağlamsal değişken olup olmadığını görmek açısından faydacı ürün reklamına yönelik olarak yapılan değerlendirmeler önem arzetmektedir. Sonuçlar incelendiğinde, ürün faydacı olduğunda bu iki faktör algısal boşluk üzerinde marjinal düzeyde $\left(F_{1,796}=3.834 ; p=.05, \eta^{2}=.498\right)$ davranışsal boşluk üzerinde ise anlamlı düzeyde birlikte bir etkiye sahiptir $\left(F_{1,796}=3.902, p=.04, \eta^{2}=.505\right)$. Zira faktörlerin tek başına etkileri incelendiğinde de faydacı ürün için bireylerin kültürel geçmişinin davranışsal boşluk üzerinde anlamlı düzeyde bir etkiye sahip olduğu görülmektedir $\left(F_{1,796}=9.195, p=\right.$ $\left..03, \eta^{2}=.857\right)$. Yine söz konusu ürün faydacı olduğunda yanlı iyimserlik düzeyinin de davranışsal boşluk üzerinde marjinal düzeyde anlamlı bir etkisi gözlenmiştir $\left(F_{1,796}=3.539\right.$, $\left.p=.06, \eta^{2}=.968\right)$. Kültürel geçmişe ve yanlı iyimserlik düzeyine dayalı olarak elde edilen anlamlı etkilerin post-hoc sonuçları ve grafikler üzerinden yorumlanması önem arzetmektedir. Bu sebeple Grafik 1'de ürün gruplarına göre kültür*yanlı iyimserlik düzeyi etkileşimi ortalama değerler üzerinden paylaşılmıştır.

Elde edilen bulgular tartışma bölümünde değerlendirilmiştir.

\section{Tartışma}

Yanlı iyimserliğin pazarlama ve reklamcılık literatürü bağlamında varlığını göstermesi ve tüketicilerin farklı ürün gruplarında cinsel içerikli reklam mesajlarına yönelik algıları ve satın alma niyetleri arasındaki ilişkiyi ele alması bakımından çalışmanın bulguları önem arzetmektedir. Faydacı ve hedonik ürün reklamlarında gözlenen üçüncü kişi etkisinin (algısal ve davranışsal boşluk) bireylerin yanlı iyimserlik düzeyleri ve kültürel geçmişlerine göre farklılaşıp farklılaşmadığını araştıran bu çalışmanın bulguları genel olarak değerlendirildiğinde, anlamlı sonuçların cinsellikle doğrudan ilgili olarak değerlendirilmeyen faydacı üründe gözlenmiş olması önemlidir. Buna göre her iki kültürdeki bireylerin de iyimserlik düzeylerine göre algısal boşlukları birbirine yakın olmakla birlikte, Türk katılımcıların nispeten kötümser olanlarının faydacı üründeki algısal boşlukları Kanadalılarınkinden daha büyüktür. Davranışsal boşlukta ise genel olarak Türk katılımcıların ortalamaları Kanadalı katılımcılardan yüksek gerçekleşmiş olmakla birlikte, Kanadalı katılımcıların nispeten iyimser olanlarının ortalamaları nispeten kötümser olan Kanadalı katılımcılardan daha yüksektir. Kendi arasında Türk katılımcılar için çok büyük farklar söz konusu değildir.

Algısal ve davranışsal boşluk kendi arasında kıyaslandığında ise satın alma niyeti gibi davranışsal bir tahminleme yapıldığında boşluğun nispeten arttığı görülmektedir. Dolayısıyla

4 Kısaltma - AB: Algısal Boşluk

5 Kısaltma - DB: Davranışsal Boşluk 

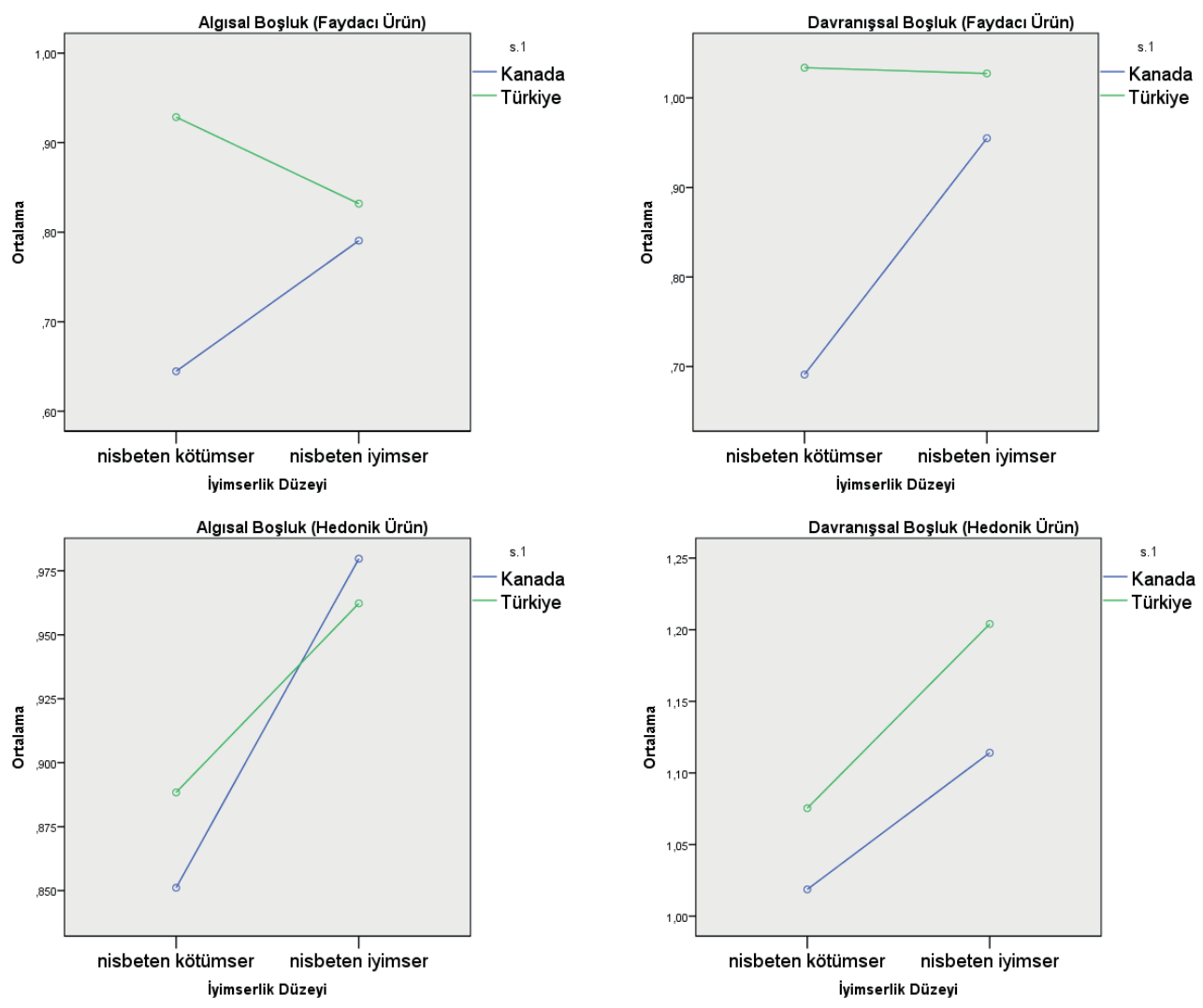

Grafik 1. Ürün gruplarına göre kültür*yanlı iyimserlik düzeyi etkileşimi

bireyler davranışsal bir sonuç söz konusu olduğunda diğerlerinin muhtemel etkilenimlerini daha yüksek ve kendilerininkini de daha düşük olarak belirtmişlerdir. Bu sonuç ürün hedonik olduğunda faydacı ürüne nazaran da daha yüksek seyretmektedir.

Sonuçların bu şekilde gerçekleşmiş olması ürün kategorisine ve bireylerin kolektivist ya da bireyci bir toplumun parçası olmalarına bağlı olarak tartışılabilir. Buna göre ürün parfüm gibi doğrudan cinsellikle ilintili algılandığında kültürlere göre kendi-diğeri ayrımında yanlı iyimserlik eğiliminin net bir etkisi gözlenemezken, diş macununda gözlenmiştir. Ancak elde edilen sonuçlara göre Türk katılımcıların kendileri ve diğerlerine yönelik yaptıkları değerlendirmeler arasındaki fark, diğer bir ifadeyle algısal boşluk Kanadalı katılımcılardan daha büyük görünmektedir. Üstelik kolektivist bir kültürün parçası olan Türklerde, beklenilenin aksine nisbeten kötümserlerin kendileri ve diğerlerine yönelik yaptıkları değerlendirmeler arasındaki fark nisbeten iyimserlerden daha yüksektir. Söz konusu davranışsal boşluk olduğunda da yine beklenilenin aksine Türk katılımcılarda gözlenen kendileri ve diğerlerine yönelik yaptıkları değerlendirmeler arasındaki fark Kanadalı ka- 
tılımcılarda gözlenenden daha yüksektir. İlginç bir şekilde Türk katılımcılardan kötümser olanların ortalamaları iyimserler olanlardan çok düşük değil hatta kimi zaman daha yüksektir. Bu noktada ise yanlı iyimserlik ölçümünde kullanılan gelecek yaşam beklentileri üzerinden bir yorumlama yapmak mümkündür.

Dolayısıyla elde edilen karmaşık bulgular bireyci ve kolektivist toplumlarda konunun çok yönlü ve farklı kültürlerde ve hatta farklı değişkenler eşliğinde ele alınmasının gerekliliğini bir kez daha vurgular niteliktedir. Zira Batıdaki kendini güçlendirme (gerçekçi olmayan iyimserlik) ve Doğudaki kendi kendini eleştirme (gerçekçi olmayan kötümserlik) alanyazında tam anlamıyla ve her koşulda ortaya koyulabilmiş ve anlaşılabilmiş bir gerçeklik değildir. Bu araştırmayla elde edilen Türkiye özelindeki öncül nitelikteki sonuçların reklam profesyonelleri, şirketler ve politika koyucular açısından katkı sağlaması beklenmektedir.

Pornpitakpan ve Green (2010) negatif yaşam olaylarına yakalanma olasılı̆̆ını yüksek gören kötümser bireylerin, önleyici reklam mesajları içeren bilgilere katlanmak konusunda daha fazla motive olduğunu ortaya koyarak, yanlı iyimserlik ve satın alma niyeti bağıntısını kalp krizi önleyici ilaç örneği üzerinden irdelemiş ve iki değişken arasında pozitif yönlü ilişki olduğunu ortaya koymuşlardır. Bu sonuç ve bulgular yanlı iyimserlik ve üçüncü kişi etkisi teorisinin, olumsuz bir deneyimi önlemeye yönelik olarak kurgulanmış ürün ve hizmetlerle (medikal ürünler, sigortacılık hizmetleri, bazı kozmetik ürünler, güvenlik ürünleri vb.) ilgili algı ve satın alma kararlarını etkileyebileceğini göstermektedir. Üstelik bu durum kültürden kültüre de değişiklik gösterebilmektedir. Pornpitakpan ve Green (2007) Amerikalı, Singapurlu ve Taylandlı ögrenciler arasında yanlı iyimserlik düzeyi ve satın alma niyeti bağlamında farklılıklar ortaya koymuşlardır. Dolayısıyla bundan sonra yapılacak olan çalışmalarda bahsi geçen ürün grupları ve farklı kültürler üzerine eğilmek, teorik bulguların potansiyel başvuru alanlarını genişletmek adına faydalı olacaktır.

Araştırma veri toplamada kolayda örnekleme ve anket yöntemi benimsemiş olması sebebiyle bir takım kısıtlar içermektedir. Öte yandan hem üçüncü kişi etkisi hem de yanlı iyimserlik konusunda araştırmaya katılanların kendi kendine rapor etmesi (self-reporting) söz konusu olduğundan bu noktada cevaplayıcıların kendileri hakkında daha olumlu değerlendirmeler yapmış olma ihtimalleri de bir diğer önemli kısıttır.

Gelecekte yapılacak araştırmalarda reklamda farklı çekicilik unsurlarının, farklı ürün grupları ve farklı kültürler bağlamında ele alınmasıyla teori ve pratik açısından önemli bir katkı sağlayacağı düşünülmektedir.

Finansal Destek: Bu çalışma Anadolu Üniversitesi BAP Komisyonu tarafından 1410E404 nolu proje kapsamında desteklenen doktora tez çalışmasından türetilmiştir. Nezahat EKİCI çalışmayı yürütmek üzere TÜBİTAK 2214/A Doktora Sırası Araştırma Bursu kapsamında desteklenmiştir. 


\section{Kaynaklar/References}

Chang, C-T., \& Tseng, C. H. (2013). Can sex sell bread? The impacts of sexual appeal type, product type and sensation seeking. International Journal of Advertising, 4(32), 559-585.

Chang, E. C., Asakawa, K., \& Sanna, L. J. (2001). Cultural variations in optimistic and pessimistic bias: Do Easterners really expect the worst and Easterners really expect the best when predicting future life events? Journal of Personality and Social Psychology, 81, 476-491.

Chapin, J. R. (2000). Not like me: Self vs. other distinctions in first-person perception. Communication Research Reports, 17(3), 320-330.

Chapin, J. R. (2013). I know you are, but what am I? Adolescents' third-person perception regarding dating violence. The Journal of Educational Research, 106, 393-398.

Chapin, J.R. (2008). Third-person perception and racism. International Journal of Communication, 2, 1-20.

Chia, S. C., \& Wen, N. (2010). College men's third-person perceptions about idealized body image and consequent behavior. Sex Roles, 63, 542-555.

Chia, S. C., Lu, K. H., \& McLeod, D. M. (2004). Sex, lies, and video compact disc: A case study on thirdperson perception and motivations for media censorship. Communication Research, 31, 109-130.

Clow, K., \& Baack, D. (2005). The Concise Encyclopedia of Advertising. Routledge.

Coelho do Vale, R., \& Duarte, J. (2013). Classification of fmcg product macro-categories on the utilitarian vs. hedonic dimensions. Laboratório de Psicologia, 11(1), 29-36.

Davison, W. P. (1983). The third-person effect in communication. Public Opinion Quarterly, 47(1), 1-15.

DeLorme, D. E., Huh, J., \& Reid, L. N. (2006). Perceived effects of direct-to-consumer (DTC) prescription drug advertising on self and others - A third-person effect study of older consumers. Journal of Advertising, 35(3), 47-65.

Eisend, M. (2008). Explaining the impact of scarcity claims in advertising: The mediating role of perceptions of susceptibility. Journal of Advertising, 37, 33-40.

Eisend, M. (2015). Persuasion knowledge and third-person perceptions in advertising: The moderating effect of regulatory competence. International Journal of Advertising, 34(1), 54-69.

Erdogan, B. Z. (2000). Constructing a practitioner-based model of selecting celebrity Endorsers (PhD Thesis). University of Strathclyde, UK.

Fontaine, K. R., \& Smith, S. (1995). Optimistic bias in cancer risk perception: A cross- national study. Psychological Reports, 77, 143-146.

Gouveia, S. O., \& Clarke,V. (2001). Optimistic bias for negative and positive events, Health Education, 101(5), 228-234.

Grazer, W. F., \& Kessling, G. (1995). The effect of print advertising's use of sexual themes on brand recall and purchase intention: A product specific investigation of male responses. Journal of Applied Business Research, 11(3), 47-57.

Gunther, A. C. (1995). Overrating the X-rating: The third-person perception and support of censorship of pornography. Journal of Communication, 45(1), 27-38.

Gunther, A., \& Mundy, P. (1993). Biased optimism and the third-person effect. Journalism Quarterly, 70, $58-67$. 
Ham, C. D., \& Nelson, M. R. (2016). The role of persuasion knowledge, assessment of benefit and harm, and third-person perception in coping with online behavioral advertising. Computers in Human Behavior, 62, 689-702.

Heine, S. J., \& Lehman, D. R. (1995). Cultural variation in unrealistic optimism: Does the west feel more invulnerable than the east? Journal of Personality and Social Psychology, 68, 595-607.

Hoffner, C., Bunchanan, M., Anderson, J. D., Hubbs, L. A., Kamigaki, S. K., Kowalczyk, L., \& Silberg, K. J. (1999). Support for censorship of television violence: The role of the third person effect and news exposure. Communication Research, 26(6), 726-742.

Hofstede, G. (2001). Culture's consequences: Comparing values, behaviors, institutions, and organizations across nations. Thousand Oaks, CA: Sage Publications.

Huge, M., Glynn, C. J., \& Jeong, I. (2006). A relationship-based approach to understanding third-person perception. Journalism and Mass Communication Quarterly, 83(3), 530-456.

Huh, J., Delorme, D., \& Reid, L. (2004). The third-person effect and its influence on behavioral outcomes in a product advertising context: The case of direct-to consumer prescription drug advertising. Communication Research, 569-590.

Hullman, G. (2008). Antecedents to the third-person perceptual effect. Northwest Communication Association Journal, 52-77.

Ismail, A. R., \& Melewar, T. C. (2014). Attitude of muslim consumers toward sex appeal in advertising: A comparative study between subcultures in Malaysia. Journal of Promotion Management, 20, 553-570.

Ji, L-J., Zhang, Z., Usborne, E., \& Guan, Y. (2004), Optimism across cultures: In response to the severe acute respiratory syndrome outbreak. Asian Journal of Social Psychology, 7(1), 25-34.

Kim, H., (2013). They will help, so I don't need to? Behavioral hypothesis of the third-person effect in donation aid advertising. Journal of Current Issues \& Research in Advertising, 30(1), 93-106.

Kitayama, S., Markus, H. R., Matsumoto, H., \& Norasakkunkit, V. (1997). Individual and collective processes in the construction of the self: Self-enhancement in the united states and self-criticism in Japan. Journal of Personality and Social Psychology, 72, 1245-1267.

Labi, R., ve Oliver, M. (2009). The influence of presumed media influence: Origins and implications of the third-person perception. N. Tal Or, Y. Tsfati, A. C. Gunther, R. 150 L. Nabi, ve M. B. Oliver (Eds.), Handbook of Media Processes and Effects içinde (99-112). Sage Publication.

Lambe, J. L., \& McLeod, D. M. (2005). Understanding third person perception processses: predicting perceived impact on self and others for multiple expressive contexts. International Communication Association, 55(2), 277-291.

Lee, B., \& Tamborini, R (2005). Third-person effect and internet pornography: The influence of collectivism and internet self-efficacy. Journal of Communication, 55, 292-10.

Lo, V. H., Wei, R., \& Wu, H. M. (2010). Examining the first, second and third-person effects of Internet pornography on taiwanese adolescents: Implications for the restriction of pornography. Asian Journal of Communication, 20(1), 90-103.

McLeod, D. M., Eveland, W. P., \& Nathanson, A. I. (1997). Support for censorship of violent and misogynic rap lyrics: An analysis of the third-person effect. Communication Research, 24(2), 153-74.

Meirick, P. C. (2004). Topic-relevant reference groups and dimensions of distance: Political advertising and first- and third-person effects. Communication Research, 31(2), 234-255. 
Paek, H. J., Pan, Z., Sun, Y., Abisaid, J., \& Houden, D. (2005). The third-person perception as social judgment: An exploration of social distance and uncertainty in perceived effects of political attack ads. Communication Research, 32(2), 143-170.

Park, J. S., Ahn, H. Y., \& Haley, E. J. (2017). Optimistic bias, advertising skepticism, and consumer intentions for seeking information about the health risks of prescription medicine, Health Marketing Quarterly, 34(2), 81-96.

Pan, P. L., Meng, J., \& Zhou, S. (2012). Examining third-person perceptions in the context of sexually oriented advertising. Journal of Promotion Management, 18, 189-208.

Peiser, W., \& Peter, J. (2001). Explaining individual differences in third-person perception: A limits/ possibilities perspective. Communication Research, 28(2), 156-180.

Perloff, R. M. (1999). The third-person effect: A critical review and synthesis. Media Psychology, 1, 353-378.

Pham, G.V, Shancer, M., \& Nelson, M.R. (2019). Only other people post food photos on Facebook: Thirdperson perception of social media behavior and effects. Computers in Human Behavior, 93,129-140.

Pornpitakpan, C., \& Green, R. T. (2007). The effect of message appeals countering unrealistic optimism on purchase intentions: A cross-national study, Asia Pacific Journal of Marketing and Logistics, 19(3), 207-226.

Pornpitakpan, C., \& Green, R.T (2010). The effect of message appeals and unrealistic optimism on purchase intentions: The case of heart-disease prevention pills, Asia Pacific Journal of Marketing and Logistics, 22(3), 372-396.

Reichert, T., Childers, C., \& Reid, L. (2012). How sex in advertising varies by product category: An analysis of three decades of visual sexual imagery in magazine advertising. Journal of Current Issues \& Research in Advertising, 33(1), 1-19.

Rose, J. P., Endo, Y., \& Windschitl, P. D. (2008). Cultural differences in unrealistic optimism and pessimism: the role of egocentrism and direct versus indirect comparison measures. Personality and Social Psychology Bulletin, 34, 1236-1248.

Rosenthal, S., Detenber, B. H., \& Rojas, H. (2018). Efficacy Beliefs in Third-Person Effects. Communication Research, 45(4), 554-576.

Salwen, M. B., \& Dupagne, M. (2003). News of Y2K and experiencing Y2K: Exploring the relationship between the third-person effect and optimistic bias. Media Psychology, 5(1), 57-82.

Salwen, M. B., \& Dupagne, M. (1999). The third-person effect. Communication Research, 26(5), 523-549.

Salwen, M.B., \& Dupagne, M. (2000). The third-person effect: a meta-analysis of the perceptual hypothesis. Mass Communication \& Society, 3, 57-85.

Scheier, M. F., \& Carver, C. S. (1992). Effects of optimism on psychological and physical well-being: Theoretical overview and empirical update. Cognitive Therapy and Research, 16, 201-228.

Schmierbach, M., Boyle, M. P., \& McLeod, D. M. (2008). Understanding person perceptions: Comparing four common statistical approaches. Mass Communication and Society, 11(4), 492-513.

Sharma, P., \& Roy, R. (2016). Looking beyond first-person effects (FPEs) in the influence of scarcity appeals in advertising: A replication and extension of Eisend (2008). Journal of Advertising, 45(1), 78-84.

Shen, L. J., Pan, Z. D., \& Sun, Y. (2010). A test of motivational vs. cognitive explanations for the third-person perception. American Journal of Media Psychology, 3, 32-53.

Shen, L., Sun, Y., \& Pan, Z. (2018) Not All Perceptual Gaps Were Created Equal: Explicating the Third- 
Person Perception (TPP) as a Cognitive Fallacy, Mass Communication and Society, 21(4), 399-424.

Shin, D. H., \& Kim, J. K. (2011). Alcohol product placements and the third-person effect. Television \& New Media, 12, 412-440.

Shiv, B., Edell, J., \& Payne, J. W. (1997). Factors affecting the impact of negatively and positively framed ad messages. Journal of Consumer Research, 24(3), 285-294.

Spangenberg, E. R., Voss, K. E., \& Crowley, A. E. (1997). Measuring the hedonic and utilitarian dimensions of attitude: A generally applicable scale. Advances in Consumer Research, 24, 235-241.

Sun, Y., Pan, Z., \& Shen, L. (2008a). Understanding the third-person perception: Evidence from a metaanalysis. Journal of Communication, 58, 280-300.

Sun, Y., Shen, L., \& Pan, Z. (2008b). On the behavioral component of the third-person effect. Communication Research, 35(2), 257-278.

Waller, D. S., Deshpande, S., \& Erdoğan, B. Z. (2013). Offensiveness of advertising with violent image appeal : A cross-cultural study. Journal of Promotion Management, 19, 400-417.

Wan, F., Faber, R. J., \& Fung, A. (2003). Perceived impact of thin female models in advertising: cultural examination of third person perception and its impact on behaviors. Asia Pacific Journal of Marketing and Logistic, 15(1), 51-73.

Wei, R., Hwei, W., \& Lu, H-Y (2007). Reconsidering the relationship between the third-person perception and optimistic bias. Communication Research, 34(6), 665-684.

Winstein, N. D (1989). Optimistic biases about personal risks. Science, 246(4935), 1232-1233.

Xie, G. X. (2016) Deceptive advertising and third-person perception: The interplay of generalized and specific suspicion. Journal of Marketing Communications, 22(5), 494-512.

Youn, S., Faber, R., \& Shah, D. (2000). Restricting gambling advertising and the third person effect. Psychology \& Marketing, 7(17), 633-649.

Youn, S., Wan, F., \& Faber, R. F. (2001). We should censor because they are vulnerable: censorship of controversial web sites and the third-person perception. In C. R. Taylor (Ed.), Proceedings of the Conference of the American Academy of Advertising (72-81). Pullman, WA: American Academy of Advertising.

Zhang, J., \& Daugherty, T. (2009). Third-person effect and social networking: Implications for online marketing and word-of mouth communication. American Journal of Business, 24(2), 53-64. 


\section{Ekler}

Ek- 1: Çalışmada kullanılan kurgusal reklamlar (Türkçe ve İngilizce)

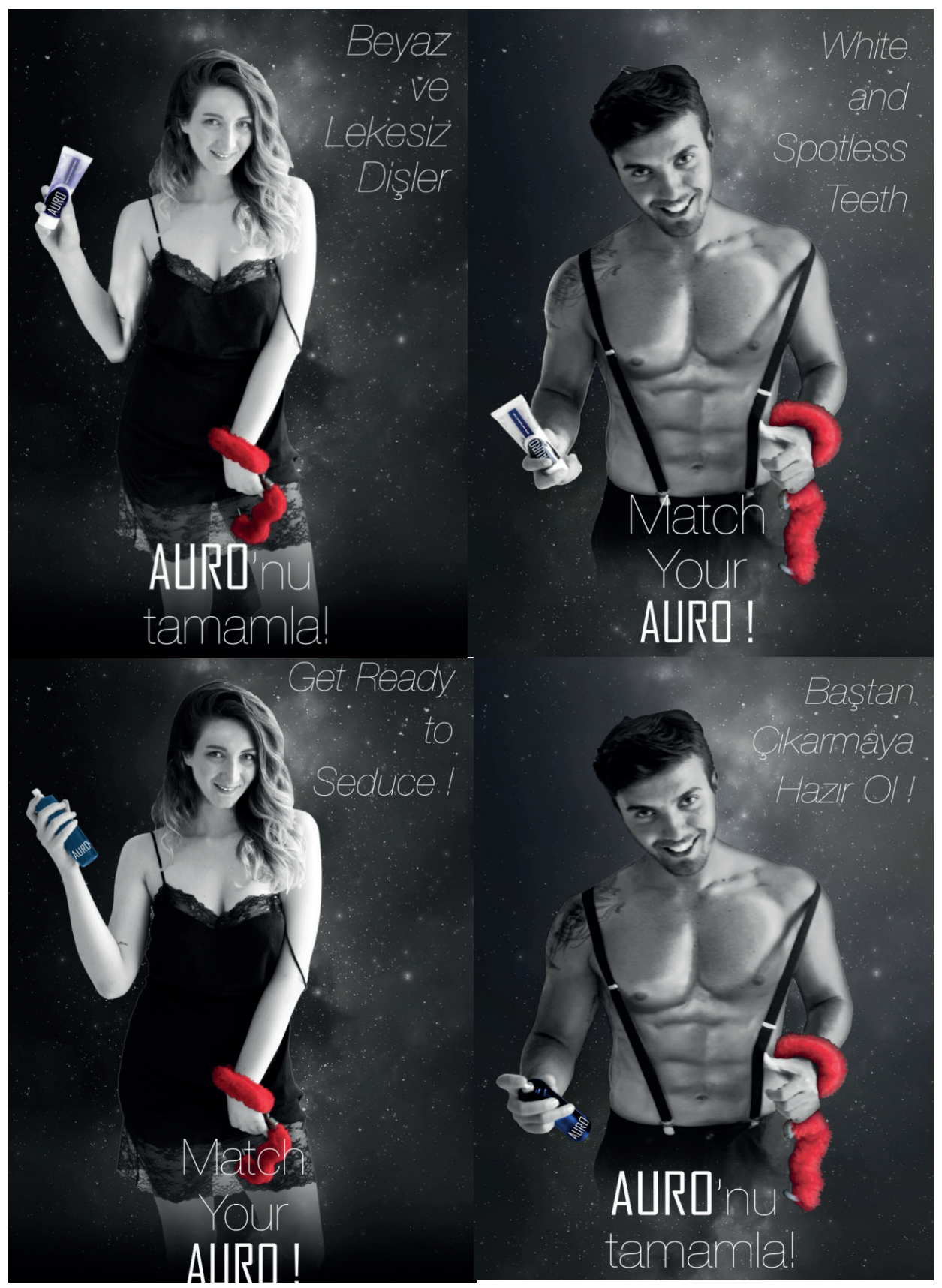

